AC 2009-67: WIRELESS APPLICATIONS IN BIOMEDICAL ENGINEERING AND TECHNOLOGY PROGRAMS AND ITS IMPACT ON ENROLLMENT AND GLOBAL ECONOMY

Rafiqul Islam, Northwestern State University 


\title{
Wireless Application in Biomedical Engineering and Technology Programs and its Impacts on Enrollment and Global Economy
}

\begin{abstract}
Wireless communications in e-healthcare is a new and promising area. Increasingly, the field of healthcare relies on computerized processes. Mechanical elements, sensors, actuators and electronics make medical devices work. More emphasis should be given to the wireless applications in the medical fields. This can be in terms of the instruments communicating with one another or the wireless networking of human-embedded sensor arrays. The goal is to develop more basic understanding of and more efficient methods for signal processing and communications in wireless biomedical sensor networks. This goal can be extended to build an in home elder healthcare system that monitors patients' medication intake. In recent years, sensor and sensor networks have been adopted as a major research focus by federal funding agencies and the private sector. Also, the advances in medical imaging techniques such as MRI (Magnetic Resonance Imaging) and PET (Positron Emission Tomography) can lead to the early diagnosis of many diseases and an increase in effectiveness of treatment and prevention.
\end{abstract}

Simultaneously, business and industry are increasingly seeking graduates with appropriate background and training in this emerging and lucrative field of biomedical engineering and technology. The United States Labor Department supports this area of concentration by forecasting a job growth of 31.4 percent through 2010 , double the rate for all other jobs combined. The aging U. S. population as well as the increase demand for improved medical devices and systems, are contributing to this increase in demand. Women will be motivated so that the stagnant or even decreasing 20 percent level of enrollment in engineering and technology fields nationwide may be lifted by understanding that the careers in this area are exciting, rewarding, satisfying and accessible. In this time of economic globalization, wireless communication in healthcare can not be ignored. Academia is also feeling pressure to contribute its share. The author will present the biomedical engineering technology concentration in the Electronics Engineering Technology program in the department of Engineering Technology of the Northwestern State University, Natchitoches, Louisiana which is one of a few ABET accredited engineering technology programs with such concentration nationwide. The overall impact on global economy will also be presented. Knowledge of this crucial field will broaden the undergraduate experience of technology and enhance their employment opportunities very greatly.

\section{Introduction}

The application of wireless biological sensor networks (WBSN) for health monitoring, have drawn a lot of interest among academia and industry. The development of a cost effective flexible platform for multiple sensors will allow easy customization, energy efficient computation, communications and increased reuse ${ }^{1}$. According to a study the population of age 65 and older will grow from 10.6 million in 1975 to 18.2 million in 
2005. The growth rate is $72 \%$ while the overall population increase is about $60 \%$. As the global trend is very similar we can share our achievements in this field with the rest of the world ${ }^{2}$. At the same time the increasing acuity and accuracy of the image generating procedures is improving the diagnosis and treatment of the patient. More emphasis should be given in the research and development of advanced ultrasound imaging for diagnostic and therapeutic applications. The relatively low cost and the avoidance of exposure of the patient to the harmful radiation are the two main attractions. As women constitute $50 \%$ of the population, an increase in women choosing careers in these fields could help cure the predicted shortfall in the professional workplace. However, young women are not choosing the other fields of engineering at the same rate as young men. We hope this field will attract more females as it makes a combination of biology and engineering and also increases the proportion of male and female students in the classroom environment ${ }^{3}$. Many of the recent advances in medicine are the results of close collaborations between medical personnel and engineers. Biological engineering is a cross-disciplinary field of engineering which includes other branches of traditional engineering. The author has sensed a clear urgency of developing a BS program in biomedical engineering Technology.

\section{The Role of Academia}

The goal of the biomedical engineering and technology programs in the universities and the colleges is to train the students in a traditional engineering while obtaining knowledge in biological and medical science. Biomedical engineering is a fast-moving and fast growing field that presents unique challenges to education professionals. To meet this growing trend it is imperative for academic institutions to provide high quality education programs with training in biomedical engineering and technology. It is hard to imagine that any major research university would be without a significant focus in BME. The author has noticed the development of many biological engineering programs throughout the last decade. But there are a few biomedical engineering technology programs in the BS degree level that have been developed to address the need of qualified technologists in this field. The author has helped to design a biomedical concentration in an exciting electronic engineering technology program with the possibility of developing a full BS program in the near future.

At Northwestern State University in Natchitoches Louisiana, we have two concentrations namely electronics and biomedical (newly added). In electronics we have two programs entitled Electronic Engineering Technology and Industrial Engineering Technology. The students will have to take 22 hours allocated for biomedical concentration. This is the minimum number of hours required by the TAC of ABET for the concentration of an area. The courses are biology, physiology, chemistry, medical instrumentation, digital signal processing and associated laboratories. The students need to take other core courses such as digital communication, classical controls, advanced electronics, microcontroller, etc. As an elective they can take a wireless communication course which is offered in the department. These courses will sharpen their knowledge in understanding wireless applications of the sensors and actuators. Students must take at least 6 hours of internships during the last two semesters before graduation. Project or 
internship experience will be designed by the student to meet their career goals. There is no specific outline for this course. Students will accomplish the following:
a. Work within the biomedical industry for no less than 180 hours.
b. Set and pursue goals and objectives in coordination with an industry mentor and the course instructor.
c. Prepare and present written and oral reports.

The undergraduate bioengineering enrollment is increasing rapidly starting in 2001 and beyond in comparison to a slow increase of overall undergraduate engineering enrollment. The enrollment in the graduate level is even more encouraging ${ }^{4}$.

Figure 1 represents the typical progression of EET program with biomedical concentration.

\section{TYPICAL SEMESTER-BY-SEMESTER PROGRESSION ELECTRONICS ENGINEERING TECHNOLOGY (141), AY 2008-2009 Biomedical Concentration (141B)}

\begin{tabular}{|c|c|c|c|c|c|c|c|}
\hline $\mathbf{1}^{\text {ST }}$ YEAR & \multicolumn{7}{|c|}{$2^{\mathrm{ND}}$ YEAR } \\
\hline $\begin{array}{l}\text { Fall } \\
1^{\text {st }} \text { Semester }\end{array}$ & $\begin{array}{r}\mathrm{Se} \\
\mathrm{m} \\
\mathrm{Hr} \\
\mathrm{s}\end{array}$ & $\begin{array}{l}\text { Spring } \\
2^{\text {nd }} \text { Semester }\end{array}$ & $\begin{array}{r}\mathrm{Se} \\
\mathrm{m} \\
\mathrm{Hr} \\
\mathrm{s}\end{array}$ & $\begin{array}{l}\text { Fall } \\
1^{\text {st }} \text { Semester }\end{array}$ & $\begin{array}{r}\mathrm{Se} \\
\mathrm{m} \\
\mathrm{Hr} \\
\mathrm{s}\end{array}$ & $\begin{array}{l}\text { Spring } \\
2^{\text {nd }} \text { Semester }\end{array}$ & \\
\hline EET 1300 & 3 & EET 1320 & 3 & \begin{tabular}{|l|l} 
EET $2320^{1}$ \\
\end{tabular} & 3 & EET $3340^{2}$ & 3 \\
\hline EET 1301 & 1 & EET 1321 & 1 & EET $2321^{1}$ & 1 & EET $3341^{2}$ & 1 \\
\hline EET 1311 & 1 & EET 1330 & 3 & IET 1400 & 3 & EET $3360^{2}$ & 3 \\
\hline IET 1700 & 1 & EET 1331 & 1 & $\begin{array}{l}\text { ZOOL } 1220 \\
\text { ZOOL } 1221\end{array}$ & $\begin{array}{l}3 \\
1\end{array}$ & $\begin{array}{l}\text { EET 3361 }{ }^{2} \\
\text { ZOOL } 1230 \\
\text { ZOOL } 1231\end{array}$ & $\begin{array}{l}1 \\
3 \\
1\end{array}$ \\
\hline ENGL 1010 & 3 & ENGL 1020 & 3 & PHYS $2030^{3}$ & 3 & PHYS $2040^{4}$ & 3 \\
\hline MATH 1810 & 6 & MATH 2020 & 6 & PHYS $2031^{3}$ & 1 & PHYS $2041^{4}$ & 1 \\
\hline OR 1010 & 1 & & & & & & \\
\hline Total & 16 & Total & 17 & Total & 15 & Total & 16 \\
\hline
\end{tabular}

\begin{tabular}{|c|c|c|c|c|c|c|c|}
\hline $3^{\mathrm{RD}}$ YEAR & \multicolumn{7}{|c|}{$4^{\mathrm{TH}}$ YEAR } \\
\hline $\begin{array}{l}\text { Fall } \\
1^{\text {st }} \text { Semester }\end{array}$ & $\begin{array}{r}\mathrm{Se} \\
\mathrm{m} \\
\mathrm{Hr} \\
\mathrm{s}\end{array}$ & $\begin{array}{l}\text { Spring } \\
2^{\text {nd }} \text { Semester }\end{array}$ & $\begin{array}{r}\mathrm{Se} \\
\mathrm{m} \\
\mathrm{Hr} \\
\mathrm{s}\end{array}$ & $\begin{array}{l}\text { Fall } \\
1^{\text {st }} \text { Semester }\end{array}$ & $\begin{array}{r}\mathrm{Se} \\
\mathrm{m} \\
\mathrm{Hr} \\
\mathrm{s}\end{array}$ & $\begin{array}{l}\text { Spring } \\
2^{\text {nd }} \text { Semester }\end{array}$ & $\begin{array}{l}\mathrm{Se} \\
\mathrm{m} \\
\mathrm{Hr}\end{array}$ \\
\hline EET $3310^{1}$ & 3 & EET $4300^{2}$ & 3 & EET 4940 & 2 & BMET & \\
\hline EET $3311^{1}$ & 1 & EET $4301^{2}$ & 1 & Elective $^{6}$ & 3 & (Internship) & \\
\hline BMET $3320^{1}$ & 3 & BMET $3370^{2}$ & 3 & & & & \\
\hline BMET $3321^{1}$ & 1 & BMET $3371^{2}$ & 1 & & & & \\
\hline
\end{tabular}




\begin{tabular}{|c|c|c|c|c|c|c|c|}
\hline & & EET $4390^{2}$ & 3 & & & & \\
\hline CHEM 1070 & 3 & COMM 1010 & 3 & ECON 2000 & 3 & FA 1040 & \\
\hline CSC 1060 & 3 & & & History ${ }^{5}$ & 3 & $\mathrm{HPF}^{5}$ & 4 \\
\hline ENGL 3230 & 3 & & & IET $4750^{3}$ & 3 & $\begin{array}{c}\text { Social/Behavio } \\
\text { ral Science }\end{array}$ & 3 \\
\hline Total & 17 & Total & 14 & Total & 14 & Total & 16 \\
\hline
\end{tabular}

${ }^{1}$ Typically offered during the fall semester only

2 Typically offered during the spring semester only

${ }^{3}$ Typically offered during the fall and summer semesters only

${ }^{4}$ Typically offered during the spring and summer semesters only

${ }^{5}$ Must meet University core curriculum requirements

${ }^{6}$ Electives may be selected from any Biomedical Engineering Technology, Computer Science, Electronics Engineering Technology, or Industrial Engineering Technology courses.

Figure 1

\section{The Role of Industry}

According to the U.S Department of Labor there is a rapid rise in biomedical engineering jobs. The health care industry forms a major segment of the U.S. economy with spending expected to surpass $\$ 2$ trillion this decade. Biomedical devices represent one of the fastest growing segments of the health care technology economy. Manufacturing industries employed $38 \%$ of all biomedical engineers primarily in the pharmaceutical and medicine manufacturing and medical instruments and supplier industries. Also there are jobs in hospitals and government agencies ${ }^{5}$. There is a significant concern among academic, scientific, industry and government leaders regarding the ability of U.S. to compete in a global market. American innovation and ingenuity are respected all over the world. We need to keep the U.S. work force competitive by addressing the importance of scientific, engineering and technology education. Industries are helping the academia in their research efforts by allocating a considerable amount of money. The industries are also helping the biomedical engineers to explore the nano world to develop powerful new medical sensors, devices and diagnostics ${ }^{6}$. An array of medical imaging technologies such as CT, MRI, PET, ultrasound optical coherence tomography etc. is replacing exploratory surgery. The industries are developing small prototype palm-sized scanner to target a small area of the body which is very popular in hospitals. The imaging technology MRI is moving from the diagnostic suite to the operating room to monitor surgical procedures as they happen. Remote and robot-assisted operation even trans-Atlantic are being reported. Diagnostic Imaging system is used to get pictures of the digestive system which is inaccessible to an endoscope ${ }^{7}$. The medical imaging research centers affiliated with some universities are involved on the academic side of technology transfer efforts to help bring innovative ideas from bench to bedside. The 
imaging technology developed is then commercialized by a company ${ }^{8}$. This type of cooperation between the academia and the industry are paying off. All the life saving antibiotics, vaccines and surgeries are discovered in the laboratories after intensive research. The contribution of the primary research funding source National Institute of Health (NIH) is very much appreciated. The net result is the achievement of seven year longer life expectancy compared to $1971^{9}$. Healthcare is a vital part of any government's agenda around the world. The biomedical and the pharmaceutical companies of the United States will be able to bring a considerable amount of revenue through its subsidiaries and joint ventures worldwide.

\section{Conclusion}

Phenomenal growth in the healthcare industry has put extensive pressure on academia to open up more biological engineering and technology programs. The output of the biological industries directly benefits the health and well being of the people. We are getting old. The longevity has caused expensive age-related disabilities, diseases and therefore healthcare. It is also necessary to keep these older people on their drug schedules as they forget to take their pills. We need to address this ageing population medication needs. Wireless biomedical sensors networks will definitely overcome the limitations of unwieldy wires between the sensor and the processor unit. This would help addressing the challenges of a growing ageing population. Also, medical imaging systems are helping to continuously monitor the patient for early detection and treatment as well. The author has pointed out the importance of biomedical research funding provided by some foundations, industries and government agencies. The BMET concentration in the Electronic Engineering Technology program of NSU provides a suitable choice for the students who want to pursue medical related areas such as medical instrumentation design. In addition, some graduates will choose to pursue medical and dentistry degrees. It will definitely create unique opportunities to accelerate progress on the participation of women in engineering technology programs. It is anticipated that the employment opportunities in this field will continue to grow with further advances in medical technology. Application of wireless technology will make it even more sustainable and cost effective bringing a win-win situation for both the engineering and medical professions.

\section{Bibliography}

1) Chen xijun, Meng, M.Q.H etc. 'Design of Sensor Node Platform for Wireless Biomedical Sensor Networks' Engineering in Medicine and Biology Society, 2005. IEEE - EMBS 2005. $27^{\text {th }}$ Annual International Conference of the Volume, Issue, 17-18 Jan., 2006, PP 4662-4665.

2) Lioc Ho, Melody Moh \& Zachary Walker, etc. SIGCOMM 2005, Workshops, August 22-26, 2005, Philadelphia, PA, USA. 
3) Mani Mina, Mehrdad Razavi, McFarland Clinic, University of Iowa, 'From Electrical Engineering to Bioengineering, What is the Shortest Path? What is the Best Path?' ASEE Proceedings of annual conference held at Chicago, Illinois during June, 2006.

4) http://www.bmes.org/whitakerArchives/glance/enrollments.html

5) www.taeworldwide.com/SID-53EB8747-7FD30FEE/about_us.html

6) http://www.bmes.org/whitakerArchives. Whitaker Foundation 2004 annual report.

7) http://bmes.org/whitakerArchives/01_annual_report/practic.html

8) http://www.misc.iit.edu/mission.html

9) http:/medicaldiscoverynews.com/shows/biomedres.html. 